\title{
6 \\ Transforming Diversity Tensions: \\ Shifting Knowledge Through Arts-Based Practices
}

\author{
Geraldine (Jody) Macdonald \& Judith A. MacDonnell \\ University of Toronto
}

In this paper, the authors engage in a dialogue to illustrate their teaching practice with experiential arts-based diversity learning. The adult education theoretical frameworks of transformative learning/ unlearning and experiential learning frame the paper. Examples of experiential arts-based diversity learning include: participating in experiential role-playing during the 'animal game,' creating paper figures that represent participant diversities, and creating an impromptu human installation.

\section{Introduction}

T eaching in the $21^{\text {st }}$ century includes inviting learners to engage with the tensions posed by multiple diversities in our social worlds. These tensions play out within and between individuals, families, and local and global communities. Diversities of gender, age, race, abilities, sexual orientation, religion/ culture, employment status, family constellation, and social and economic status all identify dominant and privileged positions which, paradoxically, continue to react to and interfere with less dominant and vulnerable ones. When the faculty invites an arts-based response, it is powerful and leads to transformative unlearning and new learning. There is a growing appreciation for the value of arts-based approaches in educational inquiry (Knowles \& Cole, 2008) and the authors advocate that educators across the academy consider incorporating arts-based approaches in their teaching practice.

\section{Dialogue}

Judith: What do you mean by transformative learning?

Jody: Our challenge as faculty is to find active, creative learning strategies that can facilitate critical reflection and support our learners to challenge assumptions and open new possibilities. Transformative learning is a theory that helps me to work toward this with learners. It describes the process that learners go through when they find that their assumptions 
and beliefs about relationships, culture, institutions, and values/ethics are not shared by others. Feller et al. (2004) cite the definition of transformative learning used in the Transformative Learning Conference (2002) as "the process by which we call into question our assumed frames of reference (habits of mind or mindsets) to make them more inclusive, discriminating, open, and reflective so that they may generate beliefs and opinions that will prove more true or justified to guide action" (p. 220).

As faculty, we can't force learners toward a transformative process; it must be a process that learners voluntarily engage in. It can be a painful one, as it challenges the core of who they are as human beings and their identity in their social world (Macdonald, 2002). However, I have found that through the transformative potential of the arts, I can facilitate the creation of openings for learners; of safe spaces where they can engage with the tensions of being challenged cognitively, emotionally, affectively, or on a soul level; and finally challenged toward action, constructive action that promotes social change.

Judith: How did you come to use transformative unlearning?

Jody: As educators, we ask our learners to challenge their own self perceptions, habits of mind, or meaning schemes (Mezirow, 2000) and the way they understand self in relation to the world (Cranton, 2006). I found that I could support learners through a process I identified as transformative unlearning, a process of discernment that involves personal growth/ vulnerability, receptivity/recognition/grieving (Boyd \& Myers, 1988), and active dialogue with the self in a supportive community of learners (Macdonald, 2002). As an educator, when I invite dialogue and reflection on sensitive topics such as gay parenting, feminist perspectives, or anti-racist discourse, I recognize that learners might feel disoriented and insecure. Through arts-based activities, I am able to address the discomforts and insecurities of individual and collective learners as they engage in the process of transformative unlearning.

Judith: Personally speaking, arts-based learning is a way to face my challenges as an educator, and to face this zone of discomfort to better understand how my place in the world shapes my relationship with students and my teaching practice, and how this knowledge enhances my own capacity to teach in a way consistent with social justice goals. So it's not just about the learners; it is about challenging your own assumptions and values, and understanding how they are relevant to how you create spaces. Beyond abstract discussions about social justice, it is about having a place to identify what you are thinking and feeling about difference, identity, power, and privilege, and how you are positioned as an educator and learner in relationship to an issue in a specific context. As Ceci (2000) stresses, "[w]e can reflect on how we, as knowers, are related to what we think we know" (p. 57), since our interpretive frames shape our actions.

The arts-based activities allow you to connect thoughts and feelings, and for an articulation of embodied knowledge as we start to think about who we are in relation to the world. One of the challenges is to get beyond the binary of self and other and one of the attractions of these activities is to get beyond this binary. A critical lens (Ceci, 2000; Breunig, 2005) focuses on power and privilege, and the intersectionalities of gender, race, class, ability, and other social dynamics, to facilitate discussion around the arts-based activities. Using a critical lens is one of the ways that we can enhance transformative learning that works toward social justice goals.

Jody: How are our arts-based learning strategies, the 'creating self,' the 'animal game,' and the 'human installation' consistent with transformative practices?

Judith: I use the 'animal game' and 'creating self' activity purposefully to illustrate some of the complexities of power and privilege. The theoretical lens of the educator (Ceci, 2000; Breunig, 2005) is a crucial factor in eliciting the potential for critical reflection in the classroom setting for the learner and the collective group of learners. Both activities seem, on the surface, very simplistic tools. One involves cutting and pasting, and the other involves making animal sounds. Both activities can challenge our assump- 
tions about ourselves in the world, social norms, and how we view our identities in relation to others. We make explicit the often normative values that shape our ways of knowing and being. Encouraging dialogue initially with the self, and then in pairs, and within the large group is an essential aspect of these activities.

Jody: Would you explain the 'animal game' and 'creating self' strategies?

Judith: 'Creating self' is an arts-based activity that uses construction paper shapes and glue sticks. Each participant is handed a small plastic "baggie" containing coloured paper of various shapes, and is then invited to create a human body using a glue stick and all of the shapes. Participants are invited to consider how this exercise can represent a narrative of self, and they are asked to jot down what they are thinking, how they are feeling during the process, and how their thoughts and feelings influence their creation. After an opportunity to reflect individually, they are asked to describe their creation with a partner. This exercise has prompted quite an enthusiastic discussion for the pairs as well as the larger group, with participants thoughtfully sharing quite detailed stories about their "bodies."

The outcomes and focus of discussion vary considerably, which appears to be related to each participant's comfort level while engaging in "creative arts" and its relevance to the class. Participants may be initially reluctant, claiming that they are not "artistic." For the most part, participants become involved and reflective given the prompts that focus on cognitive, emotional, and active aspects of this exercise. Almost inevitably, surprising narratives emerge during the discussion. Students have spontaneously shared poems, related 10-minute stories about their creations, and shared details of the historical, sociocultural, and political contexts that inform their "body art," often representing their own stories or that of an imagined other.

During one session at a conference that focused on sexuality, one colleague placed her completed body on a full-sized rectangular background. As she told her story as a same-sex identified woman, our discussion raised questions of how her presentation fore grounded the person in relation to the larger community, pointing out how boundaries of self/other are not always discrete, but are continuous with communities of meaning. Prompts that ask participants to consider what is visible/invisible in the verbal descriptions of self to another, what language was used to represent aspects of identify categories such as gender, race, sexuality, and ability, can direct the discussion to normative features such as size, shape, and social dynamics of marginalization or silencing. The stories prompted by the exercise trouble dominant representations and highlight the socially constructed nature of self/identities and difference. The facilitator can enhance participants' reflection on their own social positions, use of language, and identity categories that illustrate how we may all participate in processes that privilege certain voices and communities at the expense of others. Through this process, participants are guided to critically reflect on their assumptions, open up to new appreciations of diversities, and take action in order to promote social justice.

A second activity, the 'animal game' (Public Health Alliance, 2006), also focuses on diversity and difference. Individuals are handed a small paper with a name of a barnyard animal, which they are asked not to share with others. When all participants have read their paper, they are directed to walk about the room with their eyes closed, making their animal sound, with a goal of listening for and moving toward those who sound like they do. At the end of a few minutes, the facilitator invites the group to open their eyes, and all look about. As you recall in one session the 'cows' had linked arms, the two cats had found each other while the third was dazed, the sole bird had switched from a clucking hen to a crowing rooster in desperation, and the pig was forlornly 'oinking.'

Jody: Yes, I certainly recall that session. It was a powerful learning experience. Will you explain how you handle debriefing?

Judith: Members of each animal group are asked to describe how they felt during the process and what 
it was like to find one another. While many express relief and joy at locating another member of their group, those who are alone identify feelings of frustration and isolation. Participants often cannot find each other given the majority voices. This exercise illustrates majority and minority voices and raises awareness of feelings of isolation and processes of inclusion/exclusion in terms of antiracist and diversity work. It is also about creating a space in order to enhance understanding of finding community.

Jody: It seems that these arts-based activities, although they may appear simple, actually promote deep learning about diversities. The 'human installation' is another arts-based approach that I have developed and find an effective way of ending learning activities.

Judith: So how would you describe the 'human installation?'

Jody: I see the 'human installation' as a meaningmaking activity that grounds learning, creates body learning, brings closure, creates an expression or embodied image of the collective experience, and requires negotiation and dialogue among learners. The 'human installation' is a holistic learning approach (Griffin, 1994) that is simple to explain, but causes initial anxiety.

At the beginning of the class, learners are advised that they will be invited to create a human installation at the end of the class. They can use themselves and any resources in the classroom to portray their collective learning experience in the class/ course. In a long course, where participants have known each other over time, ten or fifteen minutes may be given for learners to dialogue and plan their installation. Most often, a few minutes is enough preparation time, and large groups can be subdivided to create several installations. The facilitator's challenge is to step away and trust that the learners will indeed pull together and create an installation.

The learners generally are energized by this challenge, and work creatively, with shared leadership. It is hard to describe the creativity that emerges, but one human installation represented homeless people with learners as statues in various poses, standing on tables and lying on the ground, while a well dressed person walked briskly through the crowd not looking at anyone. The human installation process and outcome creates a lasting impression of the learning experience. I try to capture these expressions on camera, as they are amazingly creative.

\section{Conclusion}

This paper outlines an arts-based approach to shifting knowledge, one that the authors find dynamic, innovative, and effective. We link our arts-based practice to transformative learning theories and those which address the challenge of facilitating learning about their own diversities, and extend this critical reflection to the larger social context. We argue that our approach offers an entry point into a process that invokes critical self-reflection for learners and educators living in social worlds rife with tensions but rich with the potential to shift knowledge and transform diversity tensions.

\section{References}

Boyd, R.D. \& Myers, J.G. (1988). Transformative education. International Journal of Lifelong Education 7(4), 261-84.

Breunig, M. (2005). Turning experiential education and critical pedagogy theory into praxis. The Journal of Experiential Education, 28(2), 106 -122 .

Ceci, C. (2000). Not innocent: Relationships between knowers and knowledge. Canadian Journal of Nursing Research, 32(2), 57-73.

Cranton, P. (2006). Understanding and promoting transformative learning: A guide for educators of adults (2nd ed.). San Francisco: Jossey-Bass.

Feller, A., Jensen, A., Marie, D., Peddigrew, B., Clinchard-Speda, L., \& E. Campbell. (2004). Quadrinity learning. Journal of Transformative 
Education, 2(3), 219-230.

Griffin, V. (1994). Holistic learning/teaching in adult education: Would you play a one-string guitar? In Thelma Barer-Stein \& James A. Draper (Eds.), The craft of teaching adults. Malabar, Forida: Krieger Publishing Company.

Knowles, J. G. \& Cole, A. L. (Eds.). (2008). Handbook of the arts in qualitative research: Perspectives, methodologies, examples, and issues. Los Angeles: Sage Publications.

Macdonald, G. (2002). Transformative unlearning: Safety, discernment \& communities of learning. Nursing Inquiry, 9(3), 170-178.

Mezirow, J. (2000). Learning as transformation: Critical perspectives on a theory in progress. San Francisco: Jossey-Bass.

The Public Health Alliance (PHA) for Lesbian, Gay, Bisexual, Transsexual, Transgendered, TwoSpirited, Intersex, Queer, and Questioning Equity Workgroup, Ontario Public Health Association (OPHA). (2006). A positive space is a healthy place: Making your community health centre or public health unit inclusive to those of all sexual orientations and gender identities. Toronto: Author. Retrieved August 29, 2007, from http://www.opha.on.ca/resources/SexualHealthPaper-Jun06.pdf 